\title{
Análise com software webQDA: perspectiva dos professores na Aprendizagem Baseada em Problemas
}

\author{
Flavia Alvares, Mara Chirelli \& Danielle Pio
}

Resumo:

O objetivo deste trabalho foi apresentar a análise, com o uso do software webQDA, do processo ensino e aprendizagem na Aprendizagem Baseada em Problemas (ABP), na perspectiva de professores de enfermagem de uma Instituição de Ensino Superior do Brasil. A ABP é aplicada na Unidade Educacional Sistematizada (UES), que compõe várias atividades. A amostragem foi intencional, sendo entrevistados os professores das UES 1 e UES 2 do curso de enfermagem, no ano de 2017. No processamento dos dados trabalhou-se com o webQDA, ilustrando-se neste artigo o tema que aborda a implementação da UES na perspectiva da atividade de conferência. A aplicação do software operacionalizou os dados de forma criteriosa, sistematizada, reduzindo o tempo de codificação do material das entrevistas. Como limitação, pode-se pensar na formação dos pesquisadores acerca do alcance da dimensão que o software pode avançar em relação à análise e cruzamento dos dados, especialmente pelo volume de dados.

\section{Palavras-chave:}

aprendizagem baseada em problemas; pesquisa qualitativa; educação orientada por competências; enfermagem; docentes. 


\title{
Analysis with webQDA software: teachers' perspective on Problem-Based Learning
}

\begin{abstract}
The objective of this essay was to present the analysis, using the webQDA software, of the teaching and learning process in Problem Based Learning (PBL), from the perspective of nursing teachers of a Higher Education Institution in Brazil. The PBL is applied in the Systematized Educational Unit (SEU), which composes several activities. The sampling was intentional, and teachers of the SEU 1 and SEU 2 of the nursing course were interviewed in 2017. In data processing we worked with the webQDA. Illustrating in this article the theme that addresses the SEU implementation in the perspective of the conference activity. The software's application operationalized the data in a judicious, systematized way, reducing the coding time of the interview material. As a limitation, it is possible to think about the researchers' training relating to the extent of the software can advance in relation to the analysis and crossreferencing of the data, especially by the volume of data.
\end{abstract}

Keywords: problem-based learning; qualitative research; education based on competences; nursing; professors.

\section{Analyse avec le logiciel webQDA: le point de vue des enseignants sur l'apprentissage par problèmes}

Résumé: L'objectif de ce travail était de présenter l'analyse, à l'aide du logiciel webQDA, du processus d'enseignement et d'apprentissage en apprentissage par problèmes (ABP), du point de vue des enseignants en sciences infirmières d'un établissement d'enseignement supérieur au Brésil. Le BPA est appliqué dans l'unité d'éducation systématisée (UES), qui regroupe plusieurs activités. L'échantillonnage était intentionnel et les enseignants des cours UES 1 et UES 2 du cours de sciences infirmières ont été interrogés en 2017. Dans le traitement des données, nous avons travaillé avec le webQDA. Illustrant dans cet article le thème de la mise en œuvre de UES dans la perspective de l'activité de la conférence. L'application du logiciel a rendu les données opérationnelles de manière judicieuse et systématique, réduisant ainsi le temps de codage du matériel de l'entrevue. Comme limite, on peut penser à la formation des chercheurs sur l'ampleur du logiciel qui peut avancer par rapport à l'analyse et au croisement des données, en particulier par le volume de données.

Mots clés: apprentissage par problèmes; recherche qualitative; éducation axée sur les compétences; soins infirmiers; les enseignants.

\section{Análisis con software webQDA: perspectiva de los profesores en el Aprendizaje Basado en Problemas}

Resumen: el objetivo de este trabajo fue presentar el análisis, con el uso del software webQDA, del proceso de enseñanza y aprendizaje en el Aprendizaje Basado en Problemas (ABP), desde la perspectiva de profesores de enfermería de una Institución de Enseñanza Superior de Brasil. La ABP es aplicada en la Unidad Educativa Sistematizada (UES), que compone varias actividades. El muestreo fue intencional, siendo entrevistados los profesores de las UES 1 y UES 2 del curso de enfermería, en el año 2017. En el procesamiento de los datos se trabajó con el webQDA, presentándose en este artículo el tema que aborda la implementación de la UES desde la perspectiva de la actividad de conferencia. La aplicación del software operacionalizó los datos de forma juiciosa, sistematizada, reduciendo el tiempo de codificación del material de las entrevistas. Como limitación, se puede pensar en la formación de los investigadores acerca del alcance de la dimensión que el software puede avanzar en relación al análisis y cruce de los datos, especialmente por el volumen de datos.

Palabras clave: aprendizaje basado en problemas; investigación cualitativa; educación orientada a las competencias; enfermería; profesores. 


\section{Introdução}

As mudanças construídas no âmbito da graduação em Enfermagem buscam acompanhar as transformações das políticas de saúde e educação. Nesse cenário, aponta-se a necessidade de reorientação da formação, revendo aspectos que dêem conta da articulação ensino-serviço e das exigências das necessidades sociais e do mercado de trabalho.

Na década de 80, com o movimento sanitário brasileiro, buscava-se a construção de um novo sistema de saúde, com a finalidade de preparar as pessoas para a ação social, contribuindo com as necessidades individuais e coletivas (Sobral \& Campos, 2012; Winters, Prado, \& Heidemann, 2016).

A Lei de Diretrizes e Bases da Educação Nacional (LDB) e as Diretrizes Curriculares Nacionais (DCN) do Curso de Enfermagem consolidam a proposta da articulação entre ensino, pesquisa e assistência, aproximando a teoria da prática e a problematização das situações diárias do trabalho de forma reflexiva e integrada (Sobral \& Campos, 2012). Estas DCN buscam a formação de um enfermeiro generalista, humanista, crítico, reflexivo, capaz de resolver problemas, de trabalhar em equipe, a fim de promover cuidado individual e coletivo de maneira humanizada, com base nos princípios do Sistema Único de Saúde (SUS) (Brasil, 2001).

Em vista disso, as Instituições de Ensino Superior (IES) passam a implementar novas metodologias e estratégias de ensino e aprendizagem para formar um profissional capacitado a atuar na perspectiva do cuidado integral, humanizado e ético, como proposto nas DCN (Francisco \& Tonhom, 2012). As metodologias ativas mais utilizadas são a Aprendizagem Baseada em Problemas (ABP) e a Problematização. Focaremos nessa pesquisa a prática da ABP na implementação do currículo integrado e na abordagem dialógica de competência.

As IES brasileiras na área da saúde iniciaram suas mudanças curriculares na década de 90. A IES na qual a pesquisa foi realizada começou o processo de implantação e desenvolvimento das mudanças curriculares em 1997, com a utilização da metodologia ABP no curso de Medicina. Na Enfermagem, a primeira metodologia ativa utilizada foi a Problematização em 1998 e, a partir de 2003, adotou-se o currículo integrado e orientado pela abordagem dialógica de competência, com aplicação da ABP na Unidade Educacional Sistematizada (UES) e do Ciclo Pedagógico na Unidade de Prática Profissional (UPP) (Faculdade de Medicina de Marília, 2015a).

$\mathrm{Na}$ instituição pesquisada, a UES é realizada somente no $1^{\circ}$ e $2^{\circ}$ anos do curso de Enfermagem. Esta unidade compõe as atividades de tutoria, conferência, consultoria e atividade prática (Faculdade de Medicina de Marília, 2018).

Um dos problemas evidenciados no processo de implementação da nova proposta curricular é a heterogeneidade da formação docente, com preparo e conhecimentos 
diversos acerca das técnicas e metodologias de ensino e de trabalho com os grupos. Para que sejam viáveis as mudanças curriculares exige-se governabilidade, ou seja, da gestão em consonância com as reformas propostas na educação (Pio, Bocchi, Chirelli, Vieira, Tonhom, \& Vernasque, 2018).

\section{Referencial teórico}

As reformas que têm ocorrido incidem na dimensão instrucional da educação das profissões de saúde: introdução da ABP e os movimentos de integração disciplinar no currículo (Coelho, Padilha, \& Ribeiro, 2018). A ABP mesmo sem referenciar diretamente a Escola Nova, se alinha a esse movimento ao colocar as necessidades dos estudantes no centro da aprendizagem, valorizando o desenvolvimento de capacidades voltadas à resolução de problemas e ao dar destaque ao docente como mediador da aprendizagem (Lima, 2018).

Estudos de implantação em IES brasileiras foram realizados, posteriormente à adoção das metodologias ativas, com análise de suas fortalezas e fragilidades. As fortalezas são descritas por Costa e Menezes em uma pesquisa que revelou amadurecimento e atitude de segurança no mundo do trabalho, em egressos do curso de enfermagem da UEL (Costa \& Menezes, 2017).

Já na perspectiva de estudantes da instituição pesquisada, Marin et al. (2010) destacam como fortalezas o entendimento do paciente como um todo por meio da integração de disciplinas básicas em um mesmo problema, englobando as dimensões biopsicossociais, além da valorização do autoestudo, do trabalho em grupo e da avaliação do processo.

Costa, Tonhom e Fleury (2016) analisam a integração da UES a UPP, sendo o currículo integrado avaliado pelos estudantes como uma forma de humanizar e compreender o biopsicossocial, associado a um processo de ensino e aprendizagem que estimula o protagonismo nas ações. Mesmo com as fortalezas, os estudantes ainda encontram fragilidades em relação à abrupta mudança do método tradicional. Sentem-se perdidos na busca do conhecimento científico, o que gera insegurança e demanda um esforço maior por assumir a responsabilidade pela própria aprendizagem (Marin et al, 2010).

No currículo integrado adota-se o referencial teórico holístico com a abordagem dialógica de competência, considerando a complexidade dos seus elementos constitutivos, bem como as relações estabelecidas entre os padrões científicos, as características singulares das situações em cada cenário de trabalho e a visão dos sujeitos envolvidos nas situações. Assim, a organização nessa abordagem de competência constitui-se a partir da relação entre as disciplinas, instituindo pontes entre os saberes elaborados na resolução dos problemas cotidianos e do trabalho e os saberes 
acadêmicos. Portanto, o trabalho é o princípio norteador da formação profissional (Ribeiro, Lima \& Padilha, 2018). A partir dos movimentos de implementação da ABP na instituição, questionamos como os professores compreendem, atualmente, o processo ensino e aprendizagem na UES. Quais as potencialidades e o que precisa ser modificado na implementação da ABP, na perspectiva dos professores?

Considerando que na UES existem diversas atividades para que se construa o conhecimento para sustentar a prática profissional do enfermeiro, destaca-se, nessa pesquisa, a abordagem referente à conferência, uma vez que há pouca produção científica sobre essa estratégia de ensino no contexto de currículo integrado e na abordagem dialógica de competência. Identificou-se como pressupostos, nesse momento atual, que há diferentes conhecimentos e compreensões dos professores acerca da ABP (Faculdade de Medicina de Marília, 2015b).

Portanto, objetivamos analisar o processo de ensino e aprendizagem da atividade de conferência na UES na perspectiva dos professores do curso de Enfermagem.

\section{Método}

Trata-se de um estudo de natureza qualitativa, exploratória e descritiva. O estudo exploratório tem como objetivo analisar um problema de pesquisa pouco estudado em busca de sanar as dúvidas ou de abordar o que não foi discutido antes, com a finalidade de familiarizar-se com o fenômeno. Já o estudo descritivo possui o propósito de descrever como se manifesta um determinado acontecimento, especificando, avaliando e coletando sobre os inúmeros aspectos, dimensões e componentes (Minayo, 2013).

Este estudo foi conduzido em uma IES, situada no centro-oeste do Estado de São Paulo, Brasil. A IES dispõe de dois cursos em regime integral, Medicina e Enfermagem. Os cursos de graduação têm estrutura curricular anual, seriada, em período integral, utilizando métodos ativos de ensino-aprendizagem. Oferece, anualmente, 80 vagas para o Curso de Medicina e 40 vagas para o Curso de Enfermagem, além de cursos de pós-graduação stricto sensu (mestrado acadêmico e profissional) e lato sensu (aprimoramento profissional, residência médica e multiprofissional). O desenho curricular dos dois cursos organiza-se de forma integrada e orientado pela abordagem dialógica de competência. No $1^{\circ}$ e $2^{\circ}$ anos dos cursos de Medicina e Enfermagem e para os $3^{\circ}$ e $4^{\circ}$ anos do curso de Medicina, os cenários são: Unidade Educacional Sistematizada (UES), Unidade de Prática Profissional (UPP) e Laboratório de Prática Profissional (LPP); para o $3^{\circ}$ e $4^{\circ}$ anos do curso de Enfermagem e para o $5^{\circ}$ e a $6^{\circ}$ anos do curso de Medicina, o cenário é a UPP (Faculdade de Medicina de Marília, 2015a).

A seleção dos participantes do estudo realizou-se por julgamento/intencional, com os professores ligados ao curso de Enfermagem das UES 1 e UES 2, no ano de 2017. 
Nos cenários de UES, participam professores de várias categorias profissionais, entre eles, médicos, enfermeiros e professores das áreas básicas, denominados de tutores, conferencistas, consultores e professores de atividades práticas.

A escolha dos participantes na pesquisa qualitativa é aplicada por meio de critérios não probabilísticos. Neste projeto trabalhou-se com seleção por julgamento, em que o pesquisador elegeu os membros da população de forma intencional para agregar informações precisas e apropriadas (Churchill, 1998; Schiffman \& Kanuk, 2000).

Portanto, utilizou-se como critérios de inclusão: ser professor que desenvolve o processo de ensino-aprendizagem na tutoria, conferência, consultoria ou atividade prática no $1^{\circ}$ e $2^{\circ}$ anos, com pelo menos seis meses de experiência e atuação nestas atividades. Como critério de exclusão foi considerado a falta de experiência e atuação por menos de seis meses nos papéis acima mencionados; não ter sido professor no curso de enfermagem e não ter participado como professor do curso antes de janeiro de 2017.

Portanto, participaram sete tutores do $1^{\circ}$ ano e cinco do $2^{\circ}$ ano; três conferencistas do $1^{\circ}$ e três do $2^{\circ}$; três professores de atividade prática do $1^{\circ}$ ano e três do $2^{\circ}$; três consultores do $1^{\circ}$ ano e três do $2^{\circ}$. Tivemos, assim, 16 participantes no $1^{\circ}$ ano e 14 no $2^{\circ}$ ano. Nesse artigo daremos maior enfoque as atividades realizadas pelos conferencistas.

A coleta de dados foi realizada, após a aprovação do projeto pelo Comitê de Ética da instituição pesquisada, com o Parecer n 1.321.635, seguindo a regulamentação do Comitê Nacional de Pesquisa (CNP), resolução n 466, de 12 de dezembro de 2012. Ocorreu no período de 17 de abril a 13 de junho de 2018, por um pesquisador bolsista, tendo como objetivo sua formação em atividade científica. Realizou-se estudo piloto entre o fim do mês de março de 2018 até metade do mês de abril de 2018, com a finalidade de avaliar o instrumento. Identificou-se no piloto alguns problemas no roteiro, sendo necessário readequar algumas questões norteadoras.

Os dados foram coletados por meio da entrevista semiestruturada com um roteiro, o qual possibilitou ao entrevistado discorrer sobre o assunto, devido à constituição de perguntas fechadas e abertas. No roteiro abordou-se sobre o processo ensino e aprendizagem, o desempenho do professor e estudante, a formação do professor para atuar nas diversas atividades da UES, facilidades e dificuldades do desenvolvimento pedagógico na UES e sugestões para superar as dificuldades do professor e do processo ensino-aprendizagem.

Antes de iniciar as entrevistas, explicou-se o objetivo da pesquisa e esclareceu-se dúvidas. Posteriormente, foi entregue e solicitada a assinatura do Termo de Consentimento Livre e Esclarecido (TCLE) e autorização para o uso do gravador para posterior transcrição das falas. 
Todas as entrevistas foram realizadas nas dependências da instituição de ensino, tendo duração entre 5'49" e 53'17", com média de 16 minutos. Captou-se que houve variação no tempo de realização da entrevista ocasionada pela pouca interatividade com o pesquisador, por parte de alguns entrevistados, durante a coleta de dados. $\mathrm{O}$ agendamento das entrevistas foi por meio de solicitação de contato dos professores via secretaria da instituição.

Após as transcrições das entrevistas, iniciou-se a análise de conteúdo na modalidade temática, segundo Minayo (2013), a qual se divide em três etapas: pré-análise, exploração do material ou codificação e tratamento dos resultados obtidos/interpretação (Minayo, 2013).

No processamento dos dados trabalhou-se com o software webQDA (Qualitative Data Analysis). É um software de análise de texto, áudio, imagem, ou vídeo, que depende da internet para acessar o seu projeto em qualquer computador, ou seja, não precisa de instalação, o que facilita o acesso. Além disso, pode ser utilizado por vários pesquisadores ao mesmo tempo, não sendo preciso o investigador esperar a contribuição de outro pesquisador em sua parte do projeto, para, posteriormente, inserir a sua cooperação. Portanto, esta ferramenta apoia e organiza a análise qualitativa e contribui na comunicação e colaboração entre os pesquisadores (Costa, Linhares, \& Souza, 2012).

Abriu-se uma pasta para esse projeto no software, inseriu-se as entrevistas por meio das "Fontes Internas" organizando os dados em pastas nominadas em tutores, consultores, conferencistas e atividades práticas. Após isso, realizou-se leitura intensa dos dados, criou-se as categorias com base no contexto, produção científica da área pesquisada e o material coletado. Posteriormente, codificou-se por meio de "código árvore", considerando as categorias a partir dos objetivos estabelecidos: 1) Processo Pedagógico; 2) Dificuldades ensino-aprendizagem; 3) Sugestões Processo ensino-aprendizagem; 4) Facilidades ensino-aprendizagem; 5) Desempenho professor; 6) Facilidades professor; 7) Dificuldades professor; 8) Sugestões dificuldades professor; 9) Desempenho estudante; 10) Facilidades desempenho estudante; 11) Dificuldades desempenho estudante; 12) Formação professor; 13) Apoio prática professor; e 14) Sugestões para dificuldades ensino-aprendizagem. A validação da codificação foi realizada por três pesquisadores, separadamente, e chegando a um consenso por meio de diálogo após a análise individual.

Na etapa seguinte, a partir dos códigos, fez-se a classificação do texto, utilizando o "código em árvore", delimitando os fragmentos das falas de cada entrevista, ou seja, as unidades de registro.

A partir do arquivo gerado com os fragmentos codificados, elaborou-se as sínteses de cada categoria, delimitou-se os núcleos de sentido, verificou-se a interrelação entre esses e agrupando-os por temas (quadro 1). 
A visualização e acesso rápido de todo o material codificado também beneficiou aos pesquisadores na elaboração dos núcleos de sentido e temas, na medida em que se pode ter uma prévia da frequência das palavras utilizadas pelo recurso "palavras mais frequentes" do webQDA (figura1).

Figura 1 - Representação das cem palavras mais frequentes, webQDA, 2018.

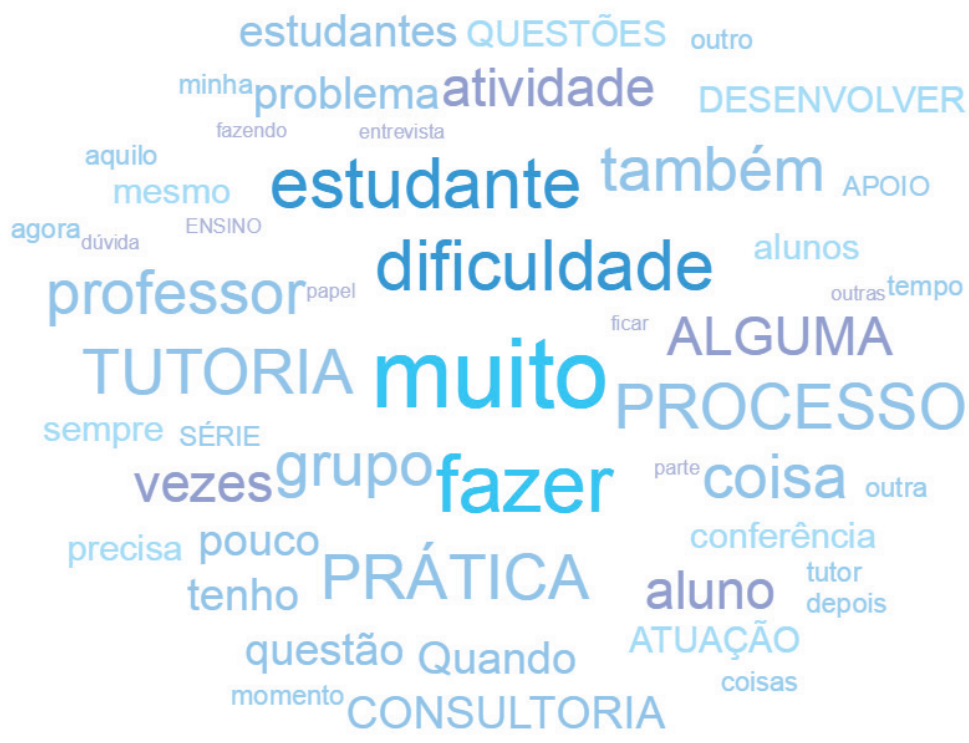

Fonte: webQDA, pesquisa

Quadro 1 - Codificação e tema resultante da pesquisa, 2018.

\begin{tabular}{|c|c|}
\hline Tema & Núcleos de Sentido \\
\hline $\begin{array}{c}\text { A Formação } \\
\text { na UES na } \\
\text { perspectiva da } \\
\text { atividade de } \\
\text { conferência }\end{array}$ & $\begin{array}{c}\text { processo ensino e aprendizagem; facilidades, dificuldades e sugestões } \\
\text { e sugestões para apoiar o conferencista; desempenho, facilidades e }\end{array}$ \\
dificuldades do estudante.
\end{tabular}

Fonte: Elaboração própria

$\mathrm{Na}$ terceira etapa realizou-se a interpretação dos dados a partir dos referenciais teóricos de educação e currículo. Ilustra-se nos resultados deste artigo o tema que aborda a formação dos professores para desenvolver o processo ensino e aprendizagem da atividade de conferencia na UES. 


\section{Resultados e Discussão}

\subsection{A Formação na UES na perspectiva da atividade de conferência}

\subsubsection{Processo ensino e aprendizagem: facilidades, dificuldades e sugestões para superação}

A IES ao implementar a ABP na formação de enfermeiras(os) tem vivenciado avanços e desafios. Uma das atividades que compõe a UES é a conferência, a qual apresenta processo ensino e aprendizagem com um modelo de organização mais tradicional de transmissão do saber na perspectiva dos professores. No entanto, há aqueles que procuram articular os conhecimentos que já foram vistos na tutoria e na UPP, compartilhando a prática deles com os novos conceitos.

"[...] tradicionalmente ela é mais uma transmissão de saber [...] mas, organizo uma conferência visando às práticas profissionais e olhando as lacunas de conhecimento, para que aquilo que eu vou estar trabalhando não seja somente uma repetição daquilo que já estudou, discutiu em tutoria, [...] do trabalhado na UPP [...]." (E2)

Foram apresentadas formas de se trabalhar na conferência, podendo ser com a lógica de raciocínio clínico e epidemiológico dos estudantes, com a realidade em que estão inseridos, trabalhar com caso de papel para possíveis discussões e construção dos conceitos, além de indicar textos para maior aprofundamento do estudo.

"Eu desenvolvo sempre na lógica de estimular os alunos a ter um grau de raciocínio com a realidade, [...] no Brasil e a realidade que eles vivem. [...] tento trazer a partir da discussão do caso os conceitos, sempre estimulando eles a fazer um assunto ampliado [...] indico pra eles sempre um texto [...] para aprofundar essas questões." (E23)

Os desafios apontados no ato da conferência associam-se as especificidades dos cursos de medicina e enfermagem, por abordar a mesma temática para diferentes cursos, justificado pelo nível de profundidade em relação aos conteúdos que são diferentes. Percebem que o desenvolvimento da atividade não satisfaz ambas as partes. Essa situação também se apresenta como um problema, porque a atividade de conferência ocorre entre todos os estudantes dos cursos de enfermagem e medicina na instituição, resultando em atividade realizada com os 120 estudantes em cada ano. 
"[...] a maior dificuldade é conseguir fazer que seja o mesmo nível pra medicina e para enfermagem, as necessidades de profundidade de um curso pro outro são diferentes, os conteúdos são diferentes e, por isso, às vezes nem sempre é fácil a gente conseguir desenvolver essa temática de maneira que satisfaça a ambas as partes [...]." (E18)

Os participantes sugerem para superação desse problema, aproximar o que é comum dos cursos e separar suas especificidades.

Os professores apontam outras formas de metodologias ativas para desenvolver a conferência, em outros modelos além da ABP, como a Problematização e a Aprendizagem Baseada em Equipes (Team Based Learning - TBL), possibilitando o trabalho com grupos grandes, com participação mais interativa e reflexiva, num contexto de transição de um modelo de formação tradicional para o interprofissional:

"[...] a conferência veio do modelo do PBL. Na Problematização [...] se aproximava muito mais das necessidades dos estudantes do que simplesmente uma conferência e era muito mais participativa [...] a própria questão da finalização TBL que existe na problematização [...] eu acho que a conferência [...] é um modelo extremamente tradicional e precisa ser repensado o modelo de educação interprofissional." (E18)

No currículo integrado e na abordagem dialógica de competência, trabalha-se a partir das necessidades do mundo do trabalho, a partir da prática profissional, de forma interdisciplinar, buscando sustentar as ações e a sua operacionalização por meio das capacidades mobilizadas de forma integrada, abordando conhecimentos, habilidades e atitudes para um desempenho competente, ético e de acordo com o grau de autonomia e domínio em cada momento da formação (Chirelli \& Nassif, 2018).

Percebe-se que os docentes têm uma preocupação com a postura ativa e de participação dos estudantes na conferência, além de demonstrarem uma preocupação na transmissão do conteúdo. No entanto, necessita-se observar se as mudanças propostas poderão favorecer uma formação crítico-reflexiva, no sentido de promover aprendizagem significativa e contribuir com a transformação da prática ou se revelará apenas um ativismo pedagógico, para dar continuidade na transmissão de conteúdos.

\subsubsection{Desempenho do professor: facilidades, dificuldades, formação e sugestões para apoiar o conferencista.}

O professor percebe que não há efeito quando a conferência é realizada de maneira teórica, conceitual e expositiva. Como facilidades são apontadas o domínio do assunto pelo docente, ter uma boa vivência da prática e as experiências. 
"[...] a conferência não pode ser muito expositiva [...] e sim pra ele fazer a reflexão da realidade da prática dele e para eles buscarem maiores conhecimentos [...] trazer um caso [...]." (E23)

"[...] é a experiência que ele tem naquele determinado assunto [...] é ele ter prática do que ele está falando." (E4)

Valadares (2013), ao investigar o ensino de física nas escolas secundárias portuguesas no século $X X$ e as mudanças com alinhamento às propostas mundiais de ensino na área, capta que houve modificações de um ensino por transmissão de conteúdos para a abordagem a partir de problemas, conectando os estudantes à realidade, possibilitando construção de análise, reflexão e busca de resolução das situações encontradas. Essa nova forma de educação está pautada no socioconstrutivismo, contextualizando as aprendizagens, constituindo a aprendizagem significativa, promovendo o diálogo durante os processos vividos por meio de trabalho em grupo, com a mediação do professor.

No ensino universitário também necessita-se avançar nos referenciais pedagógicos e nas estratégias para a construção de um conhecimento para a vida e a partir dela. $\mathrm{Na}$ perspectiva da aprendizagem significativa, pode-se acrescentar que a velocidade de agenciamento pelo sujeito de capacidades de ação é ampliada pela vivência reflexiva diante de uma variedade de situações problema em contextos diversos e da recursividade de aprendizagens em cenários singulares (Lima, Ribeiro, \& Padilha, 2018).

Percebe-se que a forma como a conferência é executada continua-se trabalhando com o isolamento de saberes considerando a fragmentação de disciplinas e a transmissão de conteúdos. Há necessidade de se rever a inserção e estratégias didáticas nessa atividade, na perspectiva das metodologias ativas e do currículo integrado. As sugestões envolvem ampliar o conhecimento do papel de um conferencista, realizá-la de forma reflexiva e investir na utilização de diferentes métodos ativos, fazendo com que os estudantes se envolvam mais.

"[...] a conferência ela tem que ser muito mais reflexiva do ponto de vista conceitual, teórico, prático, do que expositiva se não vai cair numa aula comum, uma aula que a meu ver tem pouco efeito [...]." (E23)

Os professores, de forma geral, afirmam que não houve preparo/formação para atuar como conferencista. Realizam sua prática utilizando as vivências prévias. Destacam ainda que o espaço de Educação Permanente em Saúde (EPS) é visto de forma fragmentada, com pouca oportunidade do consultor ou conferencista ser incluído no processo, tampouco abordar e trabalhar as especificidades desta atividade. 
"[...] por estar envolvida em muitos espaços de aprendizagem [...], mas não que eu tenha tido preparo para isso antes, mas baseado nas minhas vivências prévias." (E2)

"[...] então, tem a Educação Permanente para os tutores, para os professores de UPP. O consultor e o conferencista às vezes ele está numa dessas categorias [...] mas é assim, nesse espaço de EPS a gente não teria esse tempo pra poder trabalhar essa especificidade." (E2)

\subsubsection{Facilidades e dificuldades no desempenho do estudante}

Os professores percebem dificuldades com os estudantes na atividade de conferência quanto à estratégia e organização:

"[...] nosso público que abominava a conferência, que achava a pior estratégia [...] tem essa questão também, muito do horário, se a conferência foi depois de uma atividade exaustiva, ou então, muito cedo às vezes os estudantes ficam com muito sono [...]." (E2)

Mencionam que o papel do estudante é mais passivo, mesmo diante da abertura do professor para que se façam questões, sendo que a vergonha de perguntar interfere no seu desempenho, além do número de pessoas ser apontado como dificuldade para a participação dos discentes.

"[...] ele acaba sendo mais passivo, porque você está ali dando uma aula mesmo, apesar da gente abrir para as questões e você ter um número grande de pessoas dentro da sala." (E4)

As facilidades dos estudantes apresentam-se dependentes da postura do professor na conferência. Um professor traz como fator facilitador o estabelecimento de vínculo, diminuindo o receio e o constrangimento em se expor no espaço da conferência:

"[...] quando eu tenho um diálogo [...] dá um retorno do que a gente está falando [...] a gente consegue, entre aspas, quebrar um pouco o gelo, [...] ai eles fazem perguntas, [...] é porque a gente conseguiu criar um vínculo, quebrar aquele receio, constrangimento que eles têm de se expor [...]." (E22)

O perfil de competência almejado e as necessidades educacionais dos estudantes devem ser determinantes na organização das atividades a serem desenvolvidas e na dinâmica do processo de aprender. A construção do conhecimento deve ser vista sobre a força da mudança, no sentido de se fortalecer os diálogos e o processo de problematização (Soeiro, Oliveira, Schiesari, \& Oliveira, 2018). 


\subsection{Dialogando sobre a Aplicação do Software}

A aplicação do software webQDA no processamento da análise dos dados abriu oportunidade de operacionalizar o volume das entrevistas de forma criteriosa, sistematizada, reduzindo o tempo de codificação do material das entrevistas, oferecendo também cópia da codificação em arquivo.

O fato do software ser no formato online facilitou o acesso integrado de todos os pesquisadores envolvidos, possibilitando correções em tempo real, por exemplo, ao realizar a validação da codificação, acompanhar o processo de aprendizagem da bolsista frente a iniciação ao uso do software.

O webQDA como software direcionado a pesquisadores em distintos contextos, diferencia-se pela simplicidade de utilização e adaptação a diversos tipos de investigações qualitativas. Pode ser utilizado de forma individual ou colaborativamente, de forma síncrona ou assíncrona, onde o pesquisador pode editar, visualizar, interligar e organizar documentos. De forma simultânea, pode criar categorias, codificar, filtrar, procurar, questionar os dados, procurando responder aos objetivos da pesquisa (Sá \& Costa, 2017).

Para este trabalho, organizou-se os dados dos professores em pastas segundo suas funções na UES, realizou-se leitura intensa dos dados, criou-se as categorias, codificou-se por meio de "código árvore", fez-se a classificação do texto, delimitando os fragmentos das falas de cada entrevista, ou seja, as unidades de registro. Elaborou-se as sínteses de cada categoria, delimitou-se os núcleos de sentido, verificou-se a interrelação, agrupando-os por temas.

O código árvore é uma das funcionalidades do sistema de codificação, que confere ao pesquisador organização, liberdade e flexibilidade. Já demonstrado no estudo de Sá (2018), sobre o desempenho docente, que os dados podem ser processados pela codificação em árvore, com questionamento realizado por meio da triangulação entre narrativas e entrevistas, instrumentos e dados pertencentes à pesquisa. No webQDA o código é um tópico aglutinador de ideias, designado e definido pelo pesquisador (Sá \& Costa, 2017).

Considerando o que se pretendia no estudo, o software facilitou o trabalho em todas as etapas, proporcionando descrição detalhada e organizada dos dados, permitindo que ficasse clara e pormenorizada a apresentação dos resultados e as necessidades de análise crítica junto à literatura.

\section{Considerações Finais}

Pretendeu-se trazer nesse artigo uma experiência de utilização do software webQDA no processamento dos dados relacionado à implementação da UES na atividade de conferência. 
Captou-se que há necessidade de se investir na formação docente para a atividade de conferência e não apenas na prática docente na tutoria, abordando estratégias didáticas e métodos de ensino e aprendizagem que atendam a sua finalidade na implementação da UES. Precisaria trabalhar na perspectiva da inter e transdisciplinaridade como método de construção do conhecimento, articulando com as atividades da UPP, a qual insere os estudantes no mundo do trabalho, base do currículo integrado.

O uso do software para análise facilitou o processo pela sistematização e clareza na apresentação dos dados e resultados. Como limitação, identificou-se que os pesquisadores ainda precisam ampliar sua formação acerca das operações proporcionadas pelo software, para avançar em relação à articulação e análise dos dados.

Sugere-se criar grupos de consultores em cada país e/ou continente que possam oferecer apoio na operacionalização e limites na utilização inicial do software.

\section{Agradecimentos}

À Fundação de Amparo à Pesquisa do Estado de São Paulo (FAPESP) pela concessão de bolsa, processo 2017/23083-0.

\section{Referências}

Albuquerque, V. S. et al. (2008). Pressupostos da construção de um novo currículo para o curso de enfermagem. Revista Enfermagem UFPE, 2 (4), 462-473.

Brasil. (2001). Ministério da Educação, Conselho Nacional de Educação, Câmara de Educação Superior. Resolução CNE/CES n.3, de 7 de novembro de 2001. Institui diretrizes curriculares nacionais do curso de graduação em enfermagem. Diário Oficial da União, Brasília (DF); 9nov 2001; Seção 1:37.

Chirelli, M. Q., \& Nassif, J. V. (2018). A avaliação como instrumento de acompanhamento dos estudantes na graduação com metodologias ativas. In: Congresso Ibero-Americano em Investigação Qualitativa, $7^{\circ}$, Fortaleza. Atas do $7^{\circ}$ Congresso Ibero-Americano em Investigação Qualitativa - Investigação Qualitativa em Educação. (pp.213-222). Aveiro: Ludomedia.

Churchill, G. (1998) Marketing research: methodological foundations ( $2^{\mathrm{a}}$ ed). The Dryden Press.

Coelho, I. B., Padilha, R. Q., \& Ribeiro, E. C. O. (2018). Desafios na educação de profisisonais de saúde no século XXI. In: Lima, V. V., Padilha, R. Q. Reflexões e Inovações na Educação de profissionais de saúde. Rio de Janeiro: Atheneu.

Costa, A. P., Linhares, R., \& Souza, F. N. (2012). Possibilidades de análise qualitativa no webqda e colaboração entre pesquisadores em educação em comunicação. In: Simpósio Educação e Comunicação, 3., 2012. Aracaju. Anais eletrônicos [...]Aracaju: SIMEDUC, 2012. Retirado do endereço eletrônico: https://webqda.net/wpcontent/uploads/2016/10/PossibilidadesAnaliseQualitativa.pdf>.

Costa, M. C. G., Tonhom, S. F. R., \& Fleury, L.N. (2016). Ensino e aprendizagem da prática profissional: perspectiva de estudantes de medicina. Revista Brasileira Educação Médica, 40 (2), 245-253.

Costa, T. V., \& Menezes, M. H. D. G. (2017). Enfermeiros egressos do currículo integrado: inserção e atuação profissional. Revista de Enfermagem da UFPE, 11 (1), 77-85. 
Faculdade de Medicina de Marília. (2015a). Caderno de avaliação: cursos de medicina e enfermagem. Faculdade de Medicina de Marília. Marília. Retirado do endereço eletrônico: <http://www.famema. br>.

Faculdade de Medicina de Marília. (2015b). Programa de Desenvolvimento Docente. Relatórios de atividades PDD: 11/2014 a 10/2015. Marília. Retirado do endereço eletrônico: <http://www. famema.br>.

Faculdade de Medicina de Marília. (2018). Unidade Educacional 1: unidade de prática profissional e unidade educacional sistematizada. Faculdade de Medicina de Marília. Marília. Retirado do endereço eletrônico: <http://www.famema.br>.

Francisco, A. M., \& Tonhom, S. F. R. (2012). O currículo na formação do profissional em saúde. In: Moraes, M. A. A. et al. (Org.). Avaliação nos cursos de medicina e enfermagem: perspectivas e desafios. (pp.29-75).Curitiba: CRV.

Lima, V. V. (2018). Metodologias ativas de ensino-aprendizagem: desafios da inovação. In: Lima, V. V., \&Padilha, R. Q. Reflexões e Inovações na Educação de profissionais de saúde. Rio de Janeiro: Atheneu.

Marin, M. J. S. et al. (2010). Aspectos das fortalezas e fragilidades no uso das metodologias ativas de aprendizagem. Revista Brasileira Educação Médica, 34 (1), 13-20.

Minayo, M. C. S. (2013). O desafio do conhecimento: pesquisa qualitativa em saúde. (13ª ed). São Paulo (SP): Hucitec.

Pio, D. A. M. et al. (2018). A experiência formativa de professores médicos em um currículo com metodologias ativas: representação por modelo teórico. Atas do $7^{\circ}$ Congresso Ibero-Americano em Investigação Qualitativa em Educação. Aveiro: Ludomedia.

Lima, V. V., Ribeiro, E. C. O., \& Padilha, R. Q. (2018). Estrutura Curricular na formação de profissionais de saúde. In: Lima, V. V., Padilha, R. Q. Reflexões e Inovações na Educação de profissionais de saúde. Rio de Janeiro: Atheneu.

Ribeiro, E. C. de O, Lima, V. V., \& Padilha, R. Q. (2018). Formação orientada por competência. In: Lima, V. V. \& Padilha, R. de Q. Reflexões e Inovações na Educação de profissionais de saúde. Rio de Janeiro: Atheneu.

Sá, S. O. \& Costa, A. P. (2017). Análise de narrativas com software webQDA. In: Oliveira, E.S.F., Barros, N. F., Souza, D. C. D. B. N. Metodologias qualitativas em diferentes cenários: saúde e educação. Goiânia: Gráfica UFG.

Sá, S. O. (2017). A interação entre pares: que lugar na avaliação do desempenho docente? Revista Lusofóna de Educação, 37, 27-43. Doi: 10.24140/issn.1645-7250.rle37.02 Disponível em http:// revistas.ulusofona.pt/index.php/rleducacao/article/view/6228, consultado em 5 de Março de 2018.

Sobral, F. R., \& Campos, C. J. G. (2012). Utilização de metodologia ativa no ensino e assistência de enfermagem na produção nacional: revisão integrativa. Revista da Escola de Enfermagem da USP, 46 (1), 208-218. 
Valadares, J. (2013). O ensino da Física nas escolas secundárias portuguesas no século XX. Revista Lusófona de Educação, 25, 15-34. Disponível em http://revistas.ulusofona.pt/index.php/ rleducacao/article/view/4378, consultado em 5 de Março de 2018.

Winters, J. R. F., Prado, M. L., \& Heidemann, I. T. S. B. (2016). A formação em enfermagem orientada aos princípios do Sistema Único de Saúde: percepção dos formandos. Escola Anna Nery, 20 (2), 248-253.

Flávia Allegretti Alvares

Grupo de Pesquisa Educação na Saúde

Curso de Enfermagem

Faculdade de Medicina de Marília, Marília - SP, Brasil

Email: flavinha_allegretti@hotmail.com

ORCID: https://orcid.org/0000-0002-4049-3407

Mara Quaglio Chirelli

Grupo de Pesquisa Educação na Saúde

Cursos de Enfermagem e Medicina

Faculdade de Medicina de Marília, Marília - SP, Brasil

Email: marachirelli@gmail.com

ORCID: https://orcid.org/0000-0002-7417-4439

Danielle Abdel Massih Pio

Grupo de Pesquisa Educação na Saúde

Residência Integrada Multiprofissional em Saúde Mental

Cursos de Enfermagem e Medicina

Faculdade de Medicina de Marília, Marília - SP, Brasil

Email: danimassihpio@hotmail.com

ORCID: https://orcid.org/0000-0003-0738-4601

Correspondência

Mara Quaglio Chirell

Faculdade de Medicina de Marília

Unidade de Educação

Avenida José de Grande, 332, Bairro Jardim Parati

17519-470, Marília - SP, Brasi

Data de submissão: Março de 2019

Data de avaliação: Maio de 2019

Data de publicação: Julho de 2019 